\title{
Urgences
}

\section{Une bougie}

\section{Catherine Vraievie}

Numéro 20, mai 1988

\section{Appellation contrôlée}

URI : https://id.erudit.org/iderudit/025482ar

DOI : https://doi.org/10.7202/025482ar

Aller au sommaire du numéro

\section{Éditeur(s)}

Urgences

\section{ISSN}

0226-9554 (imprimé)

1927-3924 (numérique)

Découvrir la revue

\section{Citer ce document}

Vraievie, C. (1988). Une bougie. Urgences, (20), 48-49.

https://doi.org/10.7202/025482ar d'utilisation que vous pouvez consulter en ligne.

https://apropos.erudit.org/fr/usagers/politique-dutilisation/ 


\section{CATHERINE VRAIEVIE Une bougie}

Être mère, devenir sans nom. Porter le nom de l' autre, porter ses enfants. Craindre de s'approprier ses enfants: on connaît le trop grand amour des femmes qui ligotent tout ce qui a tendance à gigoter; on ne peut non plus faire la femme-enfant: on sait qu'elle est la meilleure porteuse de germes autistiques. On n'est plus la fille de sa mère, ou de son père. Le nom de l'autre, après un bref éclat, ne peut être notre nom. Comment devenir mère si c'est pour perdre son nom. Mais tient-on à un nom. Une mère n'est qu'un relais de noms.

«Où elle est maman. - J'en sais rien.»

Tentée de mettre une annonce dans le Soleil: jeune femme de trente-deux ans cherche homme jeune qui aime les fleurs, les enfants, les gâteaux, marcher à quatre pattes, pleurer une fois par semaine, inventer.

«Kiss me just like a whore. Take me up to paradise.

Il est difficile d'être mère. On ne peut être la mère qui crie des noms parce qu'on aime la délicatesse. Ni la mère fatiguée parce que la vie on n'est plus capable d'en montrer tout le vert aux grands yeux qui nous regardent. Ni la mère qui laisse à d'autres ses enfants. Ni la mère enfermée dans une maison, si enfermée qu'elle a des vertiges quand elle met le pied dans le monde.

Comment vaincre l'anonymat de la mère: faire l'éloge de l'anonymat, avoir un nom c'est être cernée par les limites du nom - un nom indique une case, avoir un nom c'est perdre la possibilité d'en avoir plusieurs, permettre à l'autre de nous coincer dans la prison d'un nom; avoir une chambre à soi, se donner un nom si souplétrange qu'il ouvre le réel au lieu de le fermer comme la plupart des noms; devenir missionnaire, psychanalyste, enseignante, la mère qui passe, sait ce qui en est des noms, vous le dit, passe, va le dire ailleurs.

«Elle a les yeux bleus, les cheveux blonds, c'est ma mère. Je me sens si bien quand elle prend ma main, c'est ma mère. Simple, douce et rassurante, elle est toujours là pour moi. Elle m'attend, lorsque je rentre je me jette dans ses bras. Je sais qu'elle est la plus belle, si je chante c'est pour elle. Comme une fleur dans le jardin elle éclaire la maison, et même quand elle a du chagrin elle le cache à sa façon**. 
Maman est-ce un nom. Maman ne donne pas de noms, elle donne des prés. Est-il vrai que lorsque nous revenons pleines de taches de monde obscur, il y a une maison avec une maman-bougie au milieu. Que faire si la maison est obscure comme le monde. On peut pleurer puis devenir une bougie, réanimer la petite flamme que nous avons vue dans les premiers yeux qui nous ont aimées.

* Les citations sont tirées de deux disques: «Colette Magny» (CBS-62416). «Colette Magny «aJe veux chaanter (Le Chant du monde, LDX 74669). 